\title{
Publishers as elements of the scientific communication system
}

\author{
Wulf D. v. Lucius
}

Published online: 13 September 2007

(C) Springer-Verlag 2007

\begin{abstract}
The author argues that the new digital possibilities in scientific communication do not imply, by any means, that many old requirements are becoming dispensable. The essential elements of the system, such as quality assurance, authenticity, orientation and navigation will still demand considerable expense. The overall system costs will rather be higher in a hybrid system. In the second part of his lecture, the author discusses the two fundamentally different open access models, the Golden Road, which is supposed to be able to operate, eventually, without any publishers, and the Green Road, whose functioning is based on primary publication through publishing houses. Finally, the basic issue of the indispensable qualitative stratigraphy of scientific documents is addressed. For this, the published journals, which also provide topical focus and, thus, orientation as well as active marketing in terms of optimal diffusion, still are a very capable tool. It is questionable to what extent these tasks could be fulfilled by university-based repositories. The publishing houses, on the other hand, have a proven track record of providing a wide range of useful value-adding services in digital publishing.
\end{abstract}

Résumé L'auteur explique que les possibilités numériques de la communication scientifique ne rendent pas le moins du monde inutiles les anciennes exigences. Les éléments indispensables du système tels que l'assurance qualité, l'authenticité, l'orientation et la navigation exigeront à l'avenir aussi des efforts considérables. Les coûts de système totaux seront donc encore plus élevés dans un système hybride. Dans la deuxième partie, l'auteur présente les deux modèles d'accès ouvert qui sont tout à fait différents, à savoir la Golden Road, qui pense pouvoir éventuellement s' arranger sans maisons d'édition, et la Green Road, dont le fonctionnement repose sur la publication primaire par des maisons d'édition. Pour terminer, le problème fondamental de l'indispensable stratigraphie qualitative des documents scientifiques

W. D. v. Lucius ( $\square)$

Lucius \& Lucius Verlagsgesellschaft mbH, Stuttgart, Germany

e-mail: lucius@luciusverlag.com 
est abordé. Les revues portées par des éditeurs se sont avérées jusqu'à aujourd'hui un moyen très probant, qui fournit en outre une focalisation thématique et par conséquent un auxiliaire d'orientation, de même que du marketing actif dans le sens d'une diffusion optimale. On peut se demander dans quelle mesure les archives universitaires ouvertes (Repositories) peuvent en faire autant. Les maisons d'édition ont déjà prouvé qu'elles sont en mesure de fournir un grand nombre de prestations utiles à valeur ajoutée dans le domaine numérique.

Zusammenfassung Der Autor erörtert, dass die neuen digitalen Möglichkeiten in der wissenschaftlichen Kommunikation viele alte Anforderungen keineswegs entbehrlich werden lassen. Die unverzichtbaren Elemente des Systems wie Qualitätssicherung, Authentizität, Orientierung und Navigation erfordern auch in Zukunft erhebliche Aufwendungen. Die Systemkosten insgesamt werden in einem Hybridsystem eher höher sein. Im zweiten Teil erörtert der Autor die zwei grundsätzlich verschiedenen Open Access-Modelle, nämlich die Golden Road, die eventuell auch ohne Verlage auskommen zu können glaubt, und die Green Road, deren Funktionieren auf der Primärpublikation durch Verlage beruht. Abschließend wird das grundlegende Problem der unabdingbaren qualitativen Stratigraphie der wissenschaftlichen Dokumente angesprochen. Dafür haben sich die verlagsgetragenen Zeitschriften bis heute als sehr taugliches Mittel erwiesen, die zudem thematische Fokussierung und damit Orientierungshilfe sowie aktives Marketing im Sinne optimaler Verbreitung leisten. Inwieweit das durch Hochschul-Repositorien geleistet werden könnte, ist fraglich. Die Verlage haben bereits bewiesen, dass sie im Digitalbereich zahlreiche nützliche Mehrwertleistungen erbringen können.

\section{New technical possibilities versus continuing requirements of the scientific community}

The immense new possibilities of knowledge storage, knowledge search and knowledge access brought by the digital revolution and, especially, the use of the Internet are accompanied by problems of their own, some of which are familiar and still need to be addressed in the digital environment, while others are new. Considering how natural it has become for us to use the Internet every day, be it as private individuals or in a professional or business capacity, we must not forget that all this has only existed for a dozen years. Never before a technical revolution has taken hold this rapidly and brought such deep structural changes in large areas of the economy and sciences, but also in personal lives. The digital revolution opened up possibilities that would have or had been dismissed as fantasies just 30 years before. However, there are still more than a few open questions that remain unanswered or are untested yet by wider practical experience.

One of the changes under particularly heated discussion entailed the question if the publishers could gradually or completely loose their function, meaning the vision that the classic, multi-stage information chain could be reduced to one simple link: author to reader. This vision assumes that the intermediate links, especially the publishers and libraries, were left without any useful function-and the publishers in 
particular are painted, sometimes in a wilfully pejorative manner, as profit skimmers and free riders. There was much conflict and gun smoke around the role of the publishers in recent years, triggered especially by the intransigent anti-publisher position of the so-called "Aktionsbündnis Urheberrecht für Bildung und Wissenschaft" around Kuhlen. If we took some of these declarations, e.g. "Budapest Declaration" (2002), the "Berliner Erklärung" (2003) or the more moderate "Göttinger Erklärung" (2004) as descriptive of the actual situation, we would have to assume that the relations between authors and publishers have totally disintegrated. Still, we see nothing of this in our everyday work as publishers: Authors keep approaching publishers with a great deal of trust and submit more of their work to the journals than ever before. As far as my own experience and what I have heard from my colleagues, there is a broad contentment with the publishers' services and contribution-even under the much more difficult conditions of recent years.

So we find a peculiar inconsistence between the confrontational positions of the Aktionsbündnis Urheberrecht für Bildung und Wissenschaft and some other science organisations, on the one hand, and the usually smooth cooperation between the individual authors with their publishers, on the other. Could it be, after all, that the present publishing functions are not that easy to replace and the publishers provide better services - mind you from the point of view of the authors' interests-than some science functionaries would like to make us believe so vocally? ${ }^{1}$ Could the entire debate turn out to be an attempt to break out from the well-tested framework of the present publication system, largely for fiscal reasons? These questions may have been raised by the possibilities of the digital publication formats, but are not uniquely connected to them. A very similar discussion could have taken place in the world of Gutenberg. In the following, we will look at the vision of the huge cost savings supposedly achieved by excluding the publishers in the digital world, the promises of efficiency involved in this exclusion, and the consequent issues of process control.

Before that, another side note: Apart from three or four international publishing groups, these horrible "profit skimming" publishers are in fact small organisations, in intense competition against each other, and operating on rather slim margins. None of them wants to be the notorious "fireman on the Diesel engine", who actually existed in 1960s' England. The publishers offer their services, know-how and structures, which any author is free to use or reject. However, as far as publishers are charged by authors with the reproduction and distribution of their work, they are entitled to full legal protection to allow them to recover their investment-even in the digital world. It is impressive to watch how the champions of the new information world cannot stop being astonished that authors continue to ask for publishers' services. Could the reason be not the authors' lack of understanding of their true interests, but the existence of considerable conceptional problems with the promised digital world of "free drinks for all"? Does the often evoked cost miracle of the Internet actually exist, and can we expect that the present publishers' services, of which many are not at all bound to the provision of tangible products, can be rendered by the universities themselves that easily? These are the questions considered in the first main part of my account.

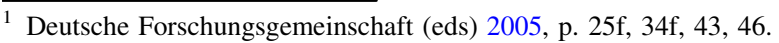




\section{What the scientific communication system needs-even in the digital world}

I am looking at the still indispensable requirements or functions that have to be fulfilled by a scientific communication system, and the inevitable costs involved. In other words, the question is if the abovementioned attempt of a fiscal breakout can be regarded as promising at all, considering the necessary maintenance of the scientific communication system. I am setting aside, for the moment, the question of who can or should provide these services. Briefly summarized, the following areas have to be considered:

\subsection{Quality control}

The direct route from the author to the reader, in particular, raises some basic questions. In science, we will still need the peer review, i.e. scientific assessment, as well as proofreading and, sometimes, considerable formatting efforts. Anything else would amount to some kind of scientific blogging, in which everybody can put anything plausible (to themselves) into the web and everybody (or, probably, nobody in most cases) will read it. I will return to this issue in the second part of my paper. However, there is no doubt that the costs for quality assurance are not at all obsolete in the digital world, but will increase significantly due to the exploding number of documents. Even if the intellectual effort of the peer review is provided by scientists, the IT-based organization of it is an expensive service that, so far, has been rendered by the publishers.

\subsection{Authenticity}

Scientific activity always builds on work done and published by others, which means it needs stable, dateable and citable documents that cannot be changed and will not just disappear some time in the future. They must be accessible at nameable locations (URLs in the web). The continuously revised, dynamic document actually belongs to the world of the factual database, where it is extremely useful. In the field of scientific publishing, though, it would be a dangerous aberration. Just think of Wikipedia, which is so hotly discussed at the moment. In science publishing there is no way around a flow of individually stored and citable documents. To this the journal, as a sorting principle, offers an excellent contribution.

\subsection{Long-term archiving}

Whoever looks at and touches an incunabulum from fifteenth century will be impressed how fresh and firm the paper is. You can easily imagine sitting down at a table with Erasmus or Melanchthon and just start reading-a nice example of perfect archiving over more than half a millennium. Now compare this to the problems of long-term archiving in the digital world: Think "Atari". Today it 
takes considerable efforts to maintain or retrieve contents that were created on now obsolete technical platforms or using obsolete software. Libraries worldwide are busied by issues such as "migration", meaning the transfer of data from an old technical environment to a new one, and "emulation", the generation of software that makes readable, e.g. Atari documents on a modern workstation. Hundreds of working groups labour over solutions and standards. Therefore, the immense convenience of universal availability of documents on the Internet, which makes it infinitely superior to the bookshelves of Erasmus, is not a natural given, but will incur yet incalculable, though, for sure, very significant future efforts and costs for keeping the system alive (Deutsche UNESCO Kommission 2007 , p. $191 \mathrm{ff}){ }^{2}$ Using the incunabulum, on the other hand, is cost-free, since it was created some 500 years ago and, simply, still exists-as viable and useable as on day 1.

Now, some may argue that knowledge is changing at such a pace today that any information from the fifteenth century or even from the first half of the twentieth century were largely irrelevant to us. Obviously, there are important variations between the faculties. In the humanities, especially theology, philosophy and art history, obsolescence is a much slower process, as reference to very old documents is essential in those fields. The extreme counter-example could be particle physics, biochemistry and computer science, where information older than 20 or 30 years is indeed of minor importance.

My own discipline, economics, may be in the middle of this spectrum. At any rate, long-term archiving will be a major cost factor for the digital scientific information system.

\subsection{Orientation and navigation}

Everyone who ever typed in "Caravaggio" (1,280,000 Google hits) or "health reform" (1,620,000 hits) as search terms knows of the need for prioritization and navigation. Even conceptual interconnections in Boolean logics, which are still not implemented in common search engines, can only offer partial remedy. The new world of information needs specialists to enable an orientation much deeper than library signatures on books and index cards for authors and subject catalogues. Librarians have long become documentalists and IT experts as well. They see themselves as navigators on the ocean of knowledge. Some such functions are also fulfilled by publishers. At a certain point in the information chain the documents need to be augmented by metadata, a process that creates further additional costs. Consequently, we need intermediate institutions (either libraries or publishers or a combination of both) not only because print products require long-term management and administration, but also for the efficient indexing and allocation of digital products for the common user.

\footnotetext{
${ }^{2}$ On the issue of sustainability, see Campbell, R./Wates, E.: Open access from the perspective of a subscription-bases publication model (in: Deutsche UNESCO Kommission 2007).
} 


\subsection{Hybrid libraries}

Paper publications offer many advantages and conveniences. After Springer had started publishing pure e-journals about 10 years ago, it took less than 3 years before librarians turned up with urgent requests for the journals to be made available in print format as well. Since then, experience has convinced the majority of specialists that "e-only" will not be the solution. Rather, a hybrid system is required, which offers the same contents in both formats, adapted for different media. This has by now become all but standard, especially for scientific journals: With the subscription of the printed journal, the library acquires, for a very modest surcharge, the digital version, which can be used on the intranet of the library or the entire campus (depending on the license taken out). For professional journals, the development goes a slightly different way. The hybrid system, in this case, often involves a print version offering an overview of the respective information while the associated digital documents or links offer consolidation and up-to-date topicality. This is where the dividing line between scientific communication and scientific publication begins to emerge: the first is possible and reasonable by purely electronic means (like a phone call), whereas for publications e-only is usually not the optimal solution, for said reasons.

The hybrid library already is reality, and it will take over many more tasks in the digital area. Consequently, the new library will by no means be cheaper than the old, paper-only library, but will involve significantly higher costs. At the same time the performance for users will be multiplied: The system of scientific information procurement will be significantly more efficient in terms of cost per user visit, while the overall system will be more expensive. In business language, we will see falling costs per information unit and rising system costs due to the explosion of usage numbers.

In my opinion, universities, librarians and scientists should tell the plain truth to the funding bodies for such a system. Failure to confront clearly and openly the misapprehension that we can look forward to real cost savings bears high risks for the supply of information. It is the same as in the health sector, where far better medical care than offered 30 years ago also entails far higher costs. Whoever denies or deliberately keeps quiet about this fact and promotes ideology-driven arguments is doing harm to the existential concerns of universities: The new, hybrid system requires significantly more funding. Digital supply of information is no panacea for cost reduction, quite the opposite; it is an area requiring large investments and high maintenance costs while allowing, in return, quite extraordinary efficiency gains of the overall system.

\subsection{Usage metrics}

Among the inherent potential facilities of a system of digital information distribution is the recordal and logging of usage. There are several initiatives to extent significantly the present citation indices, which are considered by many authors as tyranny already (partly because of the potential for manipulation by 
certain groups). One example is the MESUR project, "metrics derived from scholarly usage data", at the Los Alamos National Library. Obliviously, new agglomerations of power can emerge or be brought about deliberately in this area. It is the responsibility of the scientific community to handle this potential sensibly. Thinking of some arrangements within appointment procedures in Germany, for instance, which strongly rely on such indices, one may doubt if there is a wider awareness of this problem, especially when considering the remaining national core in the scientific publication system. The question is if international point systems are actually regarded as sensible central criteria. As a publisher I can only point to this issue, whereas the universities and research institutions are called upon to weight these criteria appropriately.

Briefly summarizing the points so far, we can state that the digital conveyance of information undoubtedly offers immense advantages, which everybody recognizes and uses. While for many publishers this area has already grown into an important and profitable field of activity, the substitution of print products by digital products has taken place only to a very small extent so far. Again we observe the phenomenon of media complementarity, where the new medium does not supersede the old one, like the wireless did not replace the concert hall and television did not replace the cinema, but joins the old medium in an often positive and invigorating interaction.

A digital-only scientific information system, on the other hand, appears to be unrealistic in the light of present user requirements. (As stated already, I am not speaking as a publisher worried about his existence, but as a neutral commentator). As a result, the reality, for a long time, will be a hybrid system, adding the extra costs of the new system (long-term archiving, metadata, navigation) to the cost of the old system (purchase of tangible products, sorting and indexing, large storage capacities and numerous staff).

Heaving dealt with the cost aspects of the system, I am now turning to the vision of free-of-charge user access and, thereby, to the role of the publishers in the digital world.

\section{Open access or: what actors do we need in the digital information system?}

What does open access actually mean $?^{3}$ Open access stands for documents that are accessible through the Internet, free-of-charge to every interested user. The legitimate and indispensable demand for free access, in the sense of unhindered access to scientific information has turned into the demand for free in the sense of free-of-charge access. This expectation was of course fed by the initial Internet euphoria, when everything seemed to be on offer at no cost, financed by advertising revenues, in particular. This vision is very tempting indeed, but let us not forget the old adage: There is no such thing as a free lunch. Even free drinks for all have to be paid for by somebody. Then think of the considerable, partly old, partly new costs incurred by the new digital information system described in the previous section.

\footnotetext{
${ }^{3}$ Deutsche UNESCO Kommission (2007) Open access. Chancen und Herausforderungen.
} 
The conclusion is clear, somebody has to pay for all this, and financing from advertising revenues will never work in the scientific domain.

One must not confuse open access with the traditional free usage of documents within universities or in the public libraries sector. In those areas, the use of the documents only appears to be cost-free while it is in fact paid for by library funds. This approach is indeed possible and widespread in the digital domain, too. The supporters of open access, however, are keen to lever out such purchases or license agreements. The national licenses presently obtained by the DFG are not connected to open access, but represent the right, acquired through a license contract, to improved provision of literature.

\subsection{The Golden Road}

We strictly discern between two models for open access, which are not just variations, but are characterized by fundamentally different operating principles. The first of these models, often referred to as the "Golden Road", postulates free-ofcharge access to documents right from the beginning. This model can work with or without publishers.

In this sense, open access means the reversal of the centuries-old financing mode of scientific information: Previously the buyers of books or the subscribers of journals financed the respective organs, which almost exclusively served to convey scientific findings. The system, therefore, was controlled by demand. Now, on the other hand, the users are supposed to not pay anything, meaning that the burden of payment is shifted to the front end of the information chain: the authors or their institutions. "Author pays" is the new motto. The Golden Road system is supplycontrolled, without any change to the costs as such.

Thus, in the absence of additional elements, open access turns out as, simply, a new business model. With open access, the author pays an entry fee, so to say, and the user enjoys the product free of charge! Imagine such a setup in the realm of theatre, the actors would pay to be allowed on stage and the audience take their seats for free. After all, without any prejudice, this could be a conceivable option. The question, however, is a social one: Would we see the better actors on stage under this system, or would we just see those who can pay for the privilege? Would the public keep visiting the new, free theatre in the long term, or would they end up preferring the traditional venues, where quality still had its price? Would, eventually, the openaccess theatre only be visited by people who are not interested at all in art etc., but like the heating of the place, and the chat during the interval, while the connoisseurs have long since decided to pay for the ticket? I am careful not to overstretch this simile, for there are some differences, of course, especially if the pre-publishing peer review keeps functioning. And we all know that many American journals have been taking so-called "page charges" and even demand a non-repayable submission fee. This applies especially to journals published by scientific societies, which serve them as strong sources of profit. Here we see that the frightful profit skimming can also occur when the authors are obliged to pay, even by non-commercial providers-no sign of working for the public benefit in this department. 
So, publishers can be relaxed about this open access model and regard it as an alternative in which they can engage as well, provided the market is not skewed decisively by increased subsidies or even statutory regulations or recommendations in favour of non-commercial providers, especially the universities themselves. Therefore, it comes as no surprise that there are many commercially managed openaccess journals or websites already in existence. Various cost calculations are based on publication costs of between \$2,000 and \$2,500 per published document. Some aggressive discounters in the commercial sector were already forced into significant price increases, naturally to the horror of the open-access euphorics. Furthermore, there are calculations telling us that a rejection rate as with Science or Nature would increase the costs per published article to about $\$ 20,000$. In the present context a few hundred Dollars more or less do not matter, but it was demonstrated above that open access is only seemingly cost-free, but actually incurs quite considerable costs. Consequently, shifting the scientific publication system to the universities as part of an open-access model would only make sense if those institutions operated more efficiently than the publishing houses (Deutsche UNESCO Kommission 2007, p. $94 \mathrm{ff})^{4}$ Generally, however, there is little evidence for any productivity advantage of the public sector over commercial providers.

So far, the full-fledged open-access model, the so-called "Golden Road".

\subsection{The Green Road}

The second way is referred to as the "Green Road", where titles initially published in classic paid-for media would be made available free-of-charge on the web, be it on the author's or the author's university server, after a certain period (6 months is an often-mentioned time scale for such schemes) ${ }^{5}$ In this case, the issue of open access narrows to the question if an amortisation period of 6 months is sufficient to cover the costs accrued. So the Green Road is based on a primary publication produced by the publishers, thereby admitting that publishers provide useful if not indispensable services for the scientific publication system (Deutsche UNESCO Kommission 2007, p. 19) ${ }^{6}$ The Green Road is about the delayed release of published contents, in the spirit of open access. This too implies a partial expropriation of the publishers, concerning the service contributions provided by them, and a decisive curtailment of their opportunities for longer-term sales, which are essential for full cost recovery in many cases.

\footnotetext{
4 s. Berger, G./Meinecke, I.: Hamburg University Press and Open Access (in: Deutsche UNESCO Kommission 2007).

5 According especially to the "Berlin Declaration on Open Access to Knowledge in the Sciences and Humanities" of 22/10/2003, which was signed by numerous science organisations.

6 On this subject, N. Lossau chose the remarkably cautious formulation: "The original signatories of the Berlin Declaration were conscious of the far-reaching importance of their demands - as well as the problems with their implementation. This explains the obvious discrepancy between the uncompromising proclamation of the principles and the guardedly worded "support for the transition to the "principle of open access" " in practice. The subsequent, still ongoing and often polemical discussion about open access and the appropriate way of implementation laid open the problems to be expected."
} 
Offering the document on the author's own website gives rise to only minor concern and should cause hardly any significant loss in the publisher's revenues. A general university repository, too, could be acceptable from the publishers' perspective.

Things become different when documents are fed into specialist full-text databases or portals. This entails considerably costs again for making such repositories user-friendly and bundling the documents in a practice-relevant manner. It would constitute unmistakably a competing publishing activity financed by public funds or, even less justifiably, the release of contents for exploitation by commercially active third parties.

Again, the question is simply, Who can do it better and at lower costs- the universities and their officials or the publishers and their specialists? Over recent years, the science publishers invested dozens of millions in new functionalities, for instance the development of the Digital Object Identifier, which makes each document permanently retrievable in the web, and the highly efficient CrossRef system by the international STM publishers, which allows access to the full text of a document, provided it is in the system, by clicking on a reference to it. The system holds millions of texts already. This vast retrospective digitalization effort alone represents a large investment by the publishers, who also created document management systems, research systems and full-text search through large databases. Another initiative of the publishers is the automated content access protocol (ACAP) presented at the Frankfurt Book Fair 2006, which will bring highly refined search mechanisms and thus could serve highly specialised suppliers and users, in particular. All this means an immense efficiency gain for scientific work, provided not by public bodies, but by the commercial participants in the system.

\subsection{Open questions about open access}

One of the tacit, but still erroneous assumptions about open access is that it will somehow automatically result in higher visibility for documents. This vision completely misses the fact that especially on the Internet, considering the millions of documents, marketing in the sense of active and structured, quality-stratified offerings is required more urgently than ever, beginning with the selection of the documents and continuing through their topical and qualitative bundling, thus creating a prestige hierarchy of publication outlets. The statement, "we can do all that cheaper ourselves" followed by the call for "Open Access" may well be somewhat premature.

The propagators of the Green Road particularly overlook, or willingly ignore that there often are intermediate, work-intensive steps, or at least significant parts of them, that are presently carried out by publishers. As an example, I can mention the convenience that publishers offer their authors by providing digitalised editing systems, as well as, for many objects, the editorial framework that attracts the readers.

A warning signal against all too euphoric expectations from university repositories was recently sounded by a study from Cornell University (Davis and 
Connolly 2007, and further references therein) which clearly states that there may have been too much effort invested in the development and installation of institutional repositories, while there was hardly any investigation into their usage by university members, neither in the contribution nor in the call-up of documents. The evaluation at Cornell comes to the conclusion that Cornell's D-space was "largely underpopulated and underused". Only the document collections, in which the university invested administrative funds, i.e. costs, were relatively successful. Discipline-specific repositories, even the personal websites of authors, were found to be clearly superior to the amorphous university server.

Similar results emerged from a study at the medical university library in Vienna (Bauer 2006):
"Open Access Publishing is regarded by many, including librarians, as an escape from the libraries and journals crisis. However, open access publishing could lead to higher costs for universities, even if journal subscriptions and licence fees would not have to be financed anymore.
There are hardly any published, detailed studies on the sustainability of the business models of BioMed Central and PLoS, or on the hybrid open access variants of the established commercial publishers. The present business models for open access publishing do not provide relief for the subscription budgets of the libraries."

Should not such empirically based critique from competent librarians lead to increased scepticism towards the seemingly cost-effective university repositories? For what is not used cannot be cost-effective. On the other hand, we have to ask the question whether the aggregation function of specialist repositories must necessarily be organised within the university system or if this previously typical publishers' function should remain where it used to be-not to enable publishers to "skim the profits", but to achieve optimum cost-efficiency of the overall system ${ }^{7}$ Fantasies, fed by idiosyncrasies, that it always must be better and cheaper to do everything yourself should be subjected to focused questioning, not least from vice-chancellors and audit authorities.

\section{The necessity of quality-stratification and selection}

Finally, we should look into a particularly important aspect, in my opinion, of open access, including control-free WEB 2.0 affairs such as Wikis, blogs, etc.- - the issue of optimal process control. Can this be undertaken by the involved parties themselves, or could the function of a neutral, "uninterested" (as far as the content is concerned) third party actually be quite useful?

Documents under the open access system will undoubtedly appear more similar to each other. The clear hierarchy of the traditional journal system becomes blurred,

\footnotetext{
7 s. the Brussels Manifesto of the STM Publishers of 13/2/2007, and the website of the Börsenverein des Deutschen Buchhandels, "Fragen und Antworten zu Open Access und Open Archive" (http://www.zweiter-korb.de).
} 
even more so if the relevant sites are run by universities (instead of third-party providers such as the publishers). For who would be the university-bases operator of an open-access range to deny their own people the option of entering paid documents? This would amount to an admission of failed training and recruitment policies. On the other hand, such necessary screening in the interest of quality assurance and user efficiency can always be provided by the demand-controlled market, run by neutral suppliers of subscription products, either print or digital. One has to be quite provocative and ask the question if science really needs pseudodemocratic equality, or if it is better served by clearly developed hierarchies of quality. This is where competition comes into play as a crucial control elementincluding the competition between conveyors of information, such as the publishers: The multitude of journals (and series) run by many publishers offers opportunities for authors to use their preferred provider or medium from which they expect the best chance of spreading their message. How is this competition supposed to work if the universities, following the call of the innovationists, were to take over all that for themselves-perhaps even by government decree?

Again, publishers have no ambition to be the fireman on the diesel engine. However, they have proven impressively over recent years that they acquired highly developed skills for running that proverbial diesel engine.

At this point, the simile of the free theatre may still be of considerable heuristic value. According to the general understanding of modern macroeconomics, resource allocation from the market should be controlled by the market or, more precisely, by demand. This means, the success and long-term survival of any journal is decided by its users. Marginal products will disappear from the market. Things are different in a supply-controlled system, where the market, provided the suppliers are solvent enough, can be flooded with a host of documents, which may not raise any concern, initially, because it is cost-free-apparently. The documents would reside on giant servers, sustained by the authors' readiness to pay. The familiar stratigraphy of the journals for certain fields would have disappeared together, perhaps, with the subtle topical organisation achieved through it.

This is a complex of issues to which a publisher can only point, but which have to be resolved by the scientific community. Without any doubt, in the digital world the topical and qualitative allocation and structuring of documents is more necessary than ever. Who is going to fulfil this and other functions? That is a completely different issue, which, however, should not be resolved through government guidance, but by competition. Especially in a tentative phase, competition is the ideal tool for answering such questions, as was shown not just by Popper and Hayek. ${ }^{8}$

In conclusion, I would like to quote the summary offered by my colleague Huter, from Vienna, in his recent report on a specialist convention?

"In my opinion, in this question too practical experience will triumph over ideology. For it turns out that in reality OA models do not (yet?) work as smoothly as assumed under ideal conditions. A study by the Association of

\footnotetext{
${ }^{8}$ v. Lucius WD (2007) Verlagswirtschaft, 2nd edn. Konstanz, p 302.

${ }^{9}$ E-University-Update Bologna. Conference on the Future of the Universities, Bonn, November 2006 (unpublished internal summary).
} 
Learned and Professional Society Publishers (ALPSP), a British not-for-profit organisation, from 2005 (http://www.alpsp.org/publications/pub11.htm) provides quite a clear picture in this respect. Scientists still prefer their publications to be handled by established publishers rather than on academic platforms of any kind. Contrary to the general suspicion towards publishing houses, the awareness is developing again of what these businesses are achieving for their customers, i.e. the producers and consumers of information products."

Therefore, my final remark is the following:

Eventually the scientists, as the producers and users of contents, will favour in their everyday decisions those providers that work best for furthering their interests. The publishers must face, and want to face this competition, as long as they are not hampered in their efforts by government coercion-be it through biased subsidies, regulation or legislation (especially concerning copyright). The publishers, with their experience and infrastructure-including the already developed new structures for the Internet-are well prepared for this challenge. In this way we could succeed in achieving the aim formulated in the first part of this paper: to combine the extraordinary new possibilities in the scientific information system with the proven functionalities and decision paths of the traditional system.

\section{References}

Bauer B (2006) Kommerzielle open access publishing-Geschäftsmodelle auf dem Prüfstand. GMS Med Bibl Inf 6(3) (Doc 32)

Davis, PhM, Connolly, MJJ (2007) Institutional repositories. Evaluating the reasons for non-use of Cornell's University's installation of D-space. D-Lib Mag 13(3)

Deutsche Forschungsgemeinschaft (eds) (2005) Publikationsstrategien im Wandel? Ergebnisse einer Umfrage, Weinheim

Deutsche UNESCO Kommission (eds) (2007) Open access. Chancen und Herausforderungen, Berlin

v. Lucius WD (2007) Verlagswirtschaft, 2nd edn. Konstanz, p 302 